\title{
Thyroid Status in Patients with Dysfunctional Uterine Bleeding in a Tertiary Care Hospital of Assam
}

\author{
1Jadab K Phukan, ${ }^{2}$ Gautom K Saharia, ${ }^{3}$ Rohini Goswami
}

\section{ABSTRACT}

Background: Dysfunctional uterine bleeding (DUB) is a major form of abnormal uterine bleeding, seen in at least $10 \%$ of all new outpatient department patients. The thyroid gland is known to play an important role in maintaining a healthy menstrual cycle.

Aims: To assess the thyroid hormone status in apparently euthyroid patients with DUB and to correlate it with incidence of DUB.

\begin{abstract}
Materials and methods: Fifty DUB patients were selected on the basis of clinical history, examination, and relevant investigations. Equal numbers of age-matched women with normal menstrual cycle were taken as controls. Thyroid hormones, viz., thyroidstimulating hormone, total triiodothyronine and tetraiodothyronine, were estimated by radioimmunoassay. Statistical analysis of the data was performed by using Microsoft Excel software.
\end{abstract}

Results: The most common menstrual abnormality was menorrhagia (48\%) followed by metrorrhagia and polymenorrhea (14\% each). Hypothyroidism was more prevalent among cases $(85.7 \%)$ as compared with controls $(14.3 \%)$. In patients with menorrhagia, $33.3 \%$ of patients had hypothyroidism.

Conclusion: Hypothyroidism occurs in DUB patients commonly. There is a need for mandatory thyroid screening in all patients with menstrual irregularities to help in early detection of the cause and treatment of DUB patients to avoid surgery.

Keywords: Assam, Dysfunctional uterine bleeding, Hypothyroidism, Menorrhagia.

How to cite this article: Phukan JK, Saharia GK, Goswami R. Thyroid Status in Patients with Dysfunctional Uterine Bleeding in a Tertiary Care Hospital of Assam. Indian J Med Biochem 2016;20(1):11-15.

Source of support: MD/MS Thesis Grant of Rs 1,50,000/(Rupees one lakh fifty thousand only) for students of North East region from the Department of Biotechnology under Ministry of Science and Technology, Government of India.

\section{Conflict of interest: None}

\footnotetext{
${ }^{1}$ Senior Resident, ${ }^{2}$ Assistant Professor, ${ }^{3}$ Professor

${ }^{1}$ Department of Biochemistry, Lokopriya Gopinath Bordoloi Regional Institute of Mental Health, Tezpur, Assam, India

${ }^{2}$ Department of Biochemistry, All India Institute of Medical Sciences, Bhubaneswar, Odisha, India

${ }^{3}$ Department of Biochemistry, Assam Medical College \& Hospital Dibrugarh, Assam, India

Correspondence Author: Gautom K Saharia, Assistant Professor, Department of Biochemistry, All India Institute of Medical Sciences, Bhubaneswar, Odisha, India, Phone: +919864440087, e-mail: gsaharia@yahoo.com
}

\section{INTRODUCTION}

Menstruation has been regarded as the purifying process of the female health system since ancient times. So, any change in the volume or pattern of menstrual bleeding is a cause of concern in women. This concern is heightened not only by the myths and taboos that surround the subject of menstruation, but also by well-orchestrated campaign for early detection of gynecological malignancies. ${ }^{1}$ Menstrual abnormalities in the absence of any organic pelvic pathology form a group of disorders known as dysfunctional uterine bleeding (DUB) or nowadays more commonly referred to as abnormal uterine bleeding, where there is a dysfunction at any level of the hypothalamo-pituitary-ovarian axis resulting in disturbance in the rhythmical production of hormones by the ovary. ${ }^{2}$ It may be bleeding without a causative uterine lesion, such as tumor infection or complications of pregnancy, although frequently there may be associated cysts of the ovary. It comprises a major portion of abnormal menstruation cases, being the principal diagnosis in at least $10 \%$ of all new outpatient department patients. ${ }^{3}$

Dysfunctional uterine bleeding is classified by the character of menstrual cycle as ovulatory or anovulatory. Out of all the etiologies, age variations and clinical presentations like thyroid dysfunction (subclinical or clinically evident) are becoming significantly important factors associated with DUB. The thyroid gland is known to play an important role in maintaining a healthy menstrual cycle. The impact of thyroid hormones has been reported to be both direct, through the presence of thyroid hormone receptors on the ovaries, and indirect, through the impact on the secretion of sex hormonebinding globulin (SHBG), prolactin, and gonadotropinreleasing hormone $(\mathrm{GnRH})$. Both hypothyroidism and hyperthyroidism are associated with a variety of changes in reproductive function including delayed onset of puberty, anovulatory cycles, and abnormally high fetal wastage. ${ }^{4}$ Clinical experiences show increased menstrual flow to be the most common reproductive system manifestation of hypothyroidism. It is seen that women with hypothyroidism had abnormal menstrual pattern, with menorrhagia or heavy menstrual bleeding being the commonest. On the contrary, hyperthyroidism 
is most commonly associated with oligomenorrhea and hypomenorrhea. ${ }^{5}$ But it is also seen that manifestations of DUB can range in between both ends of the spectrum in case of hypothyroidism. ${ }^{6}$

Abnormal menstruation, particularly heavy and prolonged menses are frequent debilitating conditions resulting in the need for repeated curettage and hysterectomy with its attendant morbidity and mortality. Hysterectomy, being a major surgery with its associated significant surgical and psychological complications, is quite unacceptable to many women today. To avoid such complications and a major surgery at all, it is better to aim at finding out an etiological factor for these abnormal bleeding patterns and treat it conservatively. The introduction of serum triiodothyronine $\left(\mathrm{T}_{3}\right)$ and tetraiodothyronine $\left(\mathrm{T}_{4}\right.$ or thyroxine) and serum thyroidstimulating hormone (TSH) radioimmunoassays has increased the sensitivity and specificity of thyroid function testing. The serum TSH assay has been shown to be a sensitive indicator of diminished thyroid functional reserve, since TSH levels become elevated before circulating serum thyroxine levels fall below the normal range. ${ }^{7}$ So, we have undertaken this study to evaluate the thyroid status in apparently euthyroid patients with DUB presenting at a tertiary care hospital in upper Assam. The correlation of thyroid dysfunction with the incidence of DUB will also be ascertained as no previous data are available regarding it in this easternmost part of the Indian subcontinent.

\section{MATERIALS AND METHODS}

The present study was undertaken at the Department of Biochemistry and Radioimmunoassay (RIA) Centre, Assam Medical College \& Hospital (AMCH), Dibrugarh, Assam, on newly diagnosed patients of DUB from July 2011 to June 2012. After obtaining approval from the Institutional Human Ethics Committee, 50 patients were selected on the basis of clinical history, examination, and relevant investigations. All the cases were in their reproductive age group, i.e., between 15 and 45 years, with menstrual abnormality in the absence of any organic pelvic pathology, attending the gynecology outpatient department or admitted in the gynecology ward of Assam Medical College \& Hospital. Equal numbers of age-matched women from similar socioeconomic background with normal menstrual cycle were taken as controls. Both the cases and controls were apparently euthyroid. The menstrual abnormalities included in this study ranged from intermenstrual bleeding or metrorrhagia, hypomenorrhea, menorrhagia, oligomenorrhea, and polymenorrhagia to polymenorrhea, which are explained in a tabular form in Table 1. All
Table 1: Different menstrual abnormalities

\begin{tabular}{|c|c|c|}
\hline $\begin{array}{l}\text { SI. } \\
\text { no. }\end{array}$ & $\begin{array}{l}\text { Menstrual } \\
\text { abnormality }\end{array}$ & Definition \\
\hline 1 & Menorrhagia & $\begin{array}{l}\text { Cyclical bleeding at normal intervals } \\
\text { that is excessive in amount or } \\
\text { duration or both. Objectively, it is a } \\
\text { total menstrual blood loss equal to or } \\
\text { greater than } 80 \mathrm{~mL} \text { per menstruation }\end{array}$ \\
\hline 2 & Polymenorrhea & $\begin{array}{l}\text { Cyclical bleeding that is normal in } \\
\text { amount but occurs at too frequent } \\
\text { intervals of less than } 21 \text { days }\end{array}$ \\
\hline 3 & Polymenorrhagia & $\begin{array}{l}\text { Cyclical bleeding that is both } \\
\text { excessive and too frequent }\end{array}$ \\
\hline 4 & Metrorrhagia & $\begin{array}{l}\text { Bleeding of any amount, i.e., } \\
\text { acyclical and that occurs irregularly } \\
\text { or continuously in between normal } \\
\text { cycles }\end{array}$ \\
\hline 5 & Menometrorrhagia & $\begin{array}{l}\text { Uterine bleeding, i.e., usually } \\
\text { excessive and prolonged occurring at } \\
\text { frequent and irregular intervals }\end{array}$ \\
\hline 6 & Hypomenorrhea & $\begin{array}{l}\text { Menstrual bleeding that is unduly } \\
\text { scanty and/or lasts for } 2 \text { days or less }\end{array}$ \\
\hline 7 & Oligomenorrhea & $\begin{array}{l}\text { Infrequent irregular episodes } \\
\text { of bleeding usually occurring at } \\
\text { intervals of more than } 35 \text { days }\end{array}$ \\
\hline 8 & Amenorrhea & $\begin{array}{l}\text { Absence of menstruation for } \\
\text { three cycle length in the setting of } \\
\text { oligomenorrhea or } 6 \text { months after } \\
\text { establishment of regular menses or } \\
18 \text { months after menarche }\end{array}$ \\
\hline
\end{tabular}

the patients were clinically diagnosed and supported by gynecological investigation/histopathology. Cases where no abnormality could be detected by abdominal and pelvic examination as well as ultrasonography were selected. Since it is difficult to measure the menstrual blood loss accurately, the cases were assessed by number of pads used, passage of clots (size and number), and duration of bleeding for the purpose of the study. ${ }^{8}$ Women on intrauterine contraceptive device or with organic lesion in genital tract like polyp, fibroid, blood dyscrasias, etc., or with history of taking steroid medication were excluded from the study. Also, patients on drugs that raise the thyroid hormone concentration like tamoxifen, amiodarone, propranolol, glucocorticoids, lithium and potassium iodide were exempt from the study. Thorough history was elicited in all cases and their investigation reports were also recorded in the questionnaire.

\section{Measurement of Thyroid Hormones}

Blood samples were collected in vacutainers under all aseptic and antiseptic conditions and serum separated by centrifugation. Estimations of $\mathrm{T}_{3}$ and $\mathrm{T}_{4}$ in serum were done by radioimmunoassay method in the RIA Centre of $\mathrm{AMCH}$, which operates under the Board of Radiation \& Isotope Technology (BRIT) of the Department of Atomic Energy, Government of India. In this procedure, RIA K-4 
and RIA K-5 kits developed by BRIT were used where unlabeled endogenous $\mathrm{T}_{3}$ or $\mathrm{T}_{4}$ competes with radiolabeled $\mathrm{T}_{3}$ or $\mathrm{T}_{4}$ for the limited binding sites on the antibody made specifically for $\mathrm{T}_{3}$ or $\mathrm{T}_{4}$ respectively. Estimations of TSH) were also done here by immunoradiometric assay (IRMA) method in antibody-coated tube along with the complementary antibody labeled with ${ }^{125}$ I using IRMAK-9 kit from BRIT. Results were calculated in gamma counter. ${ }^{9}$ Statistical analysis of the data was performed by using Microsoft Excel software. A p value of less than or equal to 0.05 was considered significant.

\section{RESULTS}

In this study, thyroid hormones of 50 cases and equal number of controls were analyzed. The mean age of study population was $32.78 \pm 9.32$ years, with a range from 15 to 45 years. Maximum number of cases and controls, i.e., $17(34 \%)$ were seen in the age group of 31 to 40 years, followed by 14 cases and controls in the 21 to 30 years age group (Table 2). It was found that maximum number of both the cases and controls $(\approx 70 \%)$ were married and parous. Graph 1 shows 50 cases that came with the complaint of different bleeding pattern, commonest being menorrhagia in $24(48 \%)$ cases. After, analyses of serum $\mathrm{TSH}, \mathrm{T}_{3}$, and $\mathrm{T}_{4}$ in both cases and controls, hypothyroid,

Table 2: Age-wise distribution of cases and controls

\begin{tabular}{llllll}
\hline & \multicolumn{3}{c}{ Cases } & & \multicolumn{2}{c}{ Controls } \\
\cline { 2 - 3 } \cline { 6 - 6 } Age group (years) & Number & $\%$ & & Number & $\%$ \\
\hline$\leq 20$ & 9 & 18 & & 9 & 18 \\
$21-30$ & 14 & 28 & & 14 & 28 \\
$31-40$ & 17 & 34 & & 17 & 34 \\
$\geq 41$ & 10 & 20 & & 10 & 20 \\
\hline Total & 50 & 100 & & 50 & 100 \\
\hline
\end{tabular}

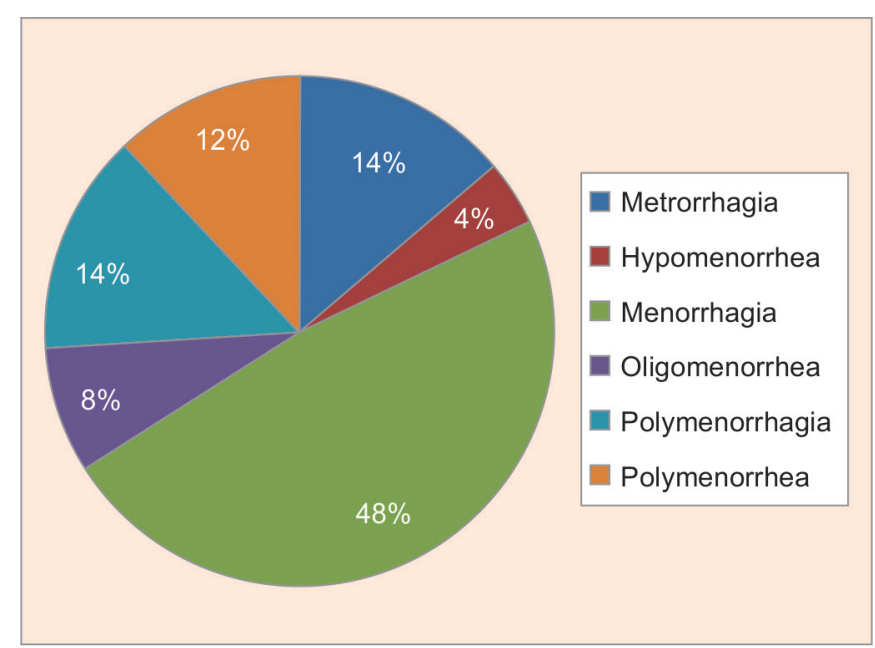

Graph 1: Distribution of cases according to bleeding pattern euthyroid as well as hyperthyroid women were detected when both groups were taken together, i.e., a total of 100 study subjects. From Table 3 it is evident that the thyroid function was significantly associated with DUB. Hypothyroidism was more prevalent among cases, i.e., $12(85.7 \%)$ as compared with 2 controls $(14.3 \%)$, which are statistically significant. Graph 2 shows the relationship of hypothyroidism, euthyroidism, and hyperthyroidism to the different bleeding patterns of clinically diagnosed cases of DUB. In patients with menorrhagia, 33.3\% of patients had hypothyroidism and $66.7 \%$ of patients were euthyroid. Table 4 shows the relation of serum TSH levels to different types of bleeding patterns where the most common bleeding patterns were menorrhagia $(41.2 \%)$ followed by polymenorrhagia (17.6\%). Likewise, it was seen that incidence of menorrhagia was higher $(\approx 45 \%)$ than other bleeding patterns where serum $\mathrm{T}_{3}$ and $\mathrm{T}_{4}$ concentrations were low.

\section{DISCUSSION}

The present study revealed that thyroid hormone levels were altered in DUB patients. From Table 2 the highest incidence was found in the 31 to 40 years age group (34\%) followed by $28 \%$ in the 21 to 30 years group. Doifode and Fernandes ${ }^{10}$ also reported maximum number of patients

Table 3: Distribution of cases and controls according to thyroid function

\begin{tabular}{|c|c|c|c|c|c|}
\hline \multirow[b]{2}{*}{ Thyroid function } & \multicolumn{2}{|c|}{ Cases } & \multicolumn{2}{|c|}{ Controls } & \multirow[b]{2}{*}{ Total } \\
\hline & Number & $\begin{array}{l}\% \text { of } \\
\text { total }\end{array}$ & Number & $\begin{array}{l}\% \text { of } \\
\text { total }\end{array}$ & \\
\hline Hypothyroid & 12 & 85.7 & 2 & 14.3 & 14 \\
\hline Euthyroid & 38 & 44.7 & 47 & 55.3 & 85 \\
\hline Hyperthyroid & 0 & 0 & 1 & 100 & 1 \\
\hline Total & 50 & - & 50 & - & 100 \\
\hline
\end{tabular}

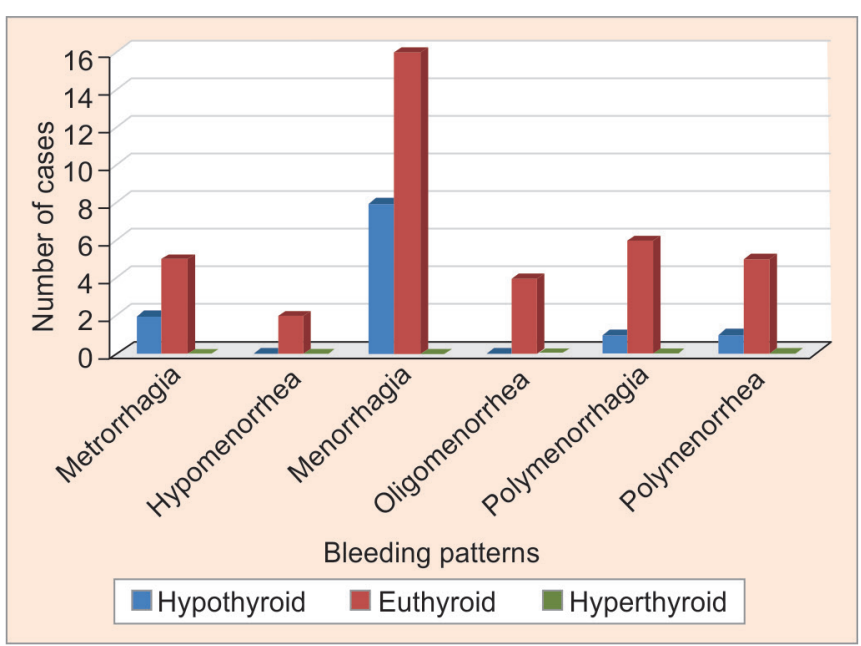

Graph 2: Bleeding patterns of hypothyroidism, euthyroidism, and hyperthyroidism cases 
Table 4: Thyroid-stimulating hormone levels and different bleeding patterns of the cases

\begin{tabular}{|c|c|c|c|c|c|c|c|c|c|c|c|c|c|}
\hline \multirow{2}{*}{$\begin{array}{l}\text { TSH levels } \\
(\mu I U / m L)\end{array}$} & \multirow{2}{*}{$\begin{array}{l}\text { No. of } \\
\text { cases }\end{array}$} & \multicolumn{2}{|c|}{ Metrorrhagia } & \multicolumn{2}{|c|}{ Hypomenorrhea } & \multicolumn{2}{|c|}{ Menorrhagia } & \multicolumn{2}{|c|}{ Oligomenorrhea } & \multicolumn{2}{|c|}{ Polymenorrhagia } & \multicolumn{2}{|c|}{ Polymenorrhea } \\
\hline & & No. & $\%$ & No. & $\%$ & No. & $\%$ & No. & $\%$ & No. & $\%$ & No. & $\%$ \\
\hline$<0.5$ & 4 & 1 & 25 & 0 & - & 2 & 50 & 1 & 25 & 0 & - & 0 & - \\
\hline $0.5-4.5$ & 34 & 4 & 11.8 & 2 & 5.9 & 14 & 41.2 & 3 & 8.8 & 6 & 17.6 & 5 & 14.7 \\
\hline $4.51-7.0$ & 10 & 2 & 20 & 0 & - & 7 & 70 & 0 & - & 1 & 10 & 0 & - \\
\hline$>7.0$ & 2 & 0 & - & 0 & - & 1 & 50 & 0 & - & 0 & - & 1 & 50 \\
\hline Total & 50 & 7 & - & 2 & - & 24 & - & 4 & - & 7 & - & 6 & - \\
\hline
\end{tabular}

belonged to age group of 31 to 40 years. This is also in accordance with Patel et $\mathrm{al}^{11}$ who stated that abnormal menstruation is more common in the third and fifth decades. He reported a similar incidence of $46 \%$ in the 21 to 30 years age group and observed that dysfunctional menstruation was more common among parous women than in nulliparous women. This was because of alterations in spiral arterioles of endometrium with age and parity, which constitutes an important local factor in hemorrhage. In the present study, $76 \%$ of the cases were parous and the commonest type of menstrual abnormality encountered was menorrhagia ( $48 \%$ ). Dass and Chugh ${ }^{12}$ reported the highest incidence in the 41 to 50 years age group, which is $32.5 \%$ followed by $28.2 \%$ incidence in the 31 to 40 years age group. Narula ${ }^{13}$ gave the highest incidence among the age group between 31 and 40 years (32.8\%) followed by the next common age group of 41 to 50 years $(29.1 \%)$.

In the present study, $24 \%$ cases (12 cases out of 50 patients) with menstrual abnormality had an abnormal thyroid function test. All of them were hypothyroid. It was seen that hypothyroidism was more prevalent among cases (12 out of 14 hypothyroid $(85.7 \%)$ ) as compared with 2 controls out of a total of $14(14.3 \%)$. Sharma and Parmar $^{14}$ and Chakrabarti et $\mathrm{al}^{15}$ have found similar incidences in their respective studies. On the contrary, Lahiri et $\mathrm{al}^{16}$ reported very high incidence of menstrual abnormality in $53 \%$ cases of hypothyroidism. Gowri et $\mathrm{al}^{17}$ found hypothyroidism in $17.6 \%$ cases but reported oligomenorrhea as the commonest abnormality. In the present study, there were no cases of hyperthyroidism with menstrual abnormality. This low incidence of cases with hyperthyroidism may be because in this part of the country, hyperthyroidism is not as common as hypothyroidism. Also, patients with hyperthyroidism present more with other symptoms of hyperthyroidism to a physician than to a gynecologist. In this study, menorrhagia was the predominant abnormality (33.3\%) in cases with hypothyroidism, followed by metrorrhagia $(28.6 \%)$. So, menorrhagia and metrorrhagia combined constituted $61.9 \%$ of the abnormal pattern, and no case of amenorrhea was reported. Scott and Mussey ${ }^{18}$ also reported menorrhagia and metrorrhagia combined as the most common irregularity in $75 \%$ cases with hypothyroidism. Singh et al ${ }^{4}$ also found that $44.4 \%$ cases with hypothyroidism presented with menorrhagia. Thus, the findings are in accordance with these studies and menorrhagia is more common in hypothyroidism. Similar findings were reported in studies where they demonstrated that menstrual irregularities were significantly more frequent in hypo- or hyperthyroidism as compared with control cases. They found that polymenorrhea is common in hypothyroidism and hypomenorrhea is common in hyperthyroidism. ${ }^{19,20}$

The menstrual irregularities and bleeding problems in hypothyroidism are attributed to multiple factors like high TSH levels or altered GnRH pulses from hypothalamus causing decrease in pituitary gonadotropin secretion or defect in luteinizing hormone secretion with persistent follicle-stimulating hormone secretion. This results in chronic anovulation in hypothyroidism or luteal phase defects in less severe cases. Anovulation resulting from either Grave's disease or myxedema disturbs the menstrual cycle. ${ }^{21}$ Hypothyroidism also alters the peripheral metabolism of estrogen and decreases SHBG production, causing rise in serum estrogen level. This, in turn, causes abnormal feedback at the pituitary level. Hypothyroidism can also lead to menorrhagia by altered production of coagulation factors (decreased levels of factors VII to IX and XI). ${ }^{19}$

\section{CONCLUSION}

The study reveals that in patients with DUB, hypothyroidism and menorrhagia predominate as presenting symptoms. It can be concluded that DUB is closely associated with thyroid dysfunctions, which can be relieved by normalization of thyroid status. So, thyroid assessment should be routinely performed in all patients with menstrual irregularities as it is seen that menstrual irregularity precedes the occurrence of other clinical symptoms of thyroid dysfunction. This will help in early detection of the cause and prompt treatment of DUB patients and definitely will have an impact on reduction in incidence of hysterectomy. 


\section{ACKNOWLEDGMENT}

Authors would like to acknowledge Dr. Ramesh Sonowal, Associate Professor, Department of Obstetrics \& Gynaecology and Mr. Partha Jyoti Hazarika, Head cum Scientific Officer, RIA Centre of Assam Medical College \& Hospital, Dibrugarh for their contributions toward selection of cases and in carrying out the thyroid investigations respectively. We are also indebted to the Department of Biotechnology, under Ministry of Science and Technology, Government of India for providing the grant to carry out the research work.

\section{REFERENCES}

1. Snow LF, Johnson SM. Modern day menstrual folklore - some clinical implications. JAMA 1977 Jun;237(25):2736-2739.

2. Berek, Jonathan S. Berek and Novak's gynecology, Chapter 14. 15th ed. Philadelphia: Lippincott Williams \& Wilkins; 2012. p. 404.

3. Keith Edmonds, D. Dewhurst's textbook of obstetrics and gynaecology for postgraduates, Chapter 42. 8th ed. Chichester: Wiley-Blackwell; 2012. p. 534-539.

4. Singh L, Agarwal CG, Choudhury SR, Mehra P, Khare R. Thyroid profile in infertile patients. J Obstet Gynaecol India 1990;40:248.

5. Koutras DA. Disturbances of menstruation in thyroid disease. Ann N Y Acad Sci 1997 Jun 17;816:280-284.

6. Krassas GE, Pontikides N, Kaltsas T, Papadopoulou P, Paunkovic J, Paunkovic N, Duntas LH. Disturbances of menstruation in hypothyroidism. Clin Endocrine 1999 May;50(5):655-659.

7. Ingbar, SH. The thyroid gland. In: Wilson, JD.; Foster, DW., eds. Textbook of endocrinology. 7th ed. Philadelphia: WB Saunders; 1985. p. 682-815.
8. Dutta, DC. Textbook of gynecology, Chapter 14. 6th ed. New Delhi: Jaypee Brothers Medical Publishers; 2013. p. 185-187.

9. Product enclosures provided with Immunoassay kits by Board of Radiation and Isotope Technology (BRIT): www.britatom. gov.in, Navi Mumbai, India.

10. Doifode CD, Fernandes K. Study of thyroid dysfunction in patients with dysfunctional uterine bleeding. J Obstet Gynaecol India 2001;51(2):93-95.

11. Patel SB, Delvadia JL, Desai DA. Clinicopathological and endocrinal correlation in cases of menstrual disturbances. NHL J Med Sci 2012;1(1):14-17.

12. Dass A, Chugh S. Dysfunctional uterine bleeding. J Obstet Gynaecol India 1964;14:348-353.

13. Narula ER. Menstrual irregularities. J Obstet Gynecol India 1967;17:164.

14. Sharma UR, Parmar C. Thyroid profile in infertile women and menstrual dysfunction. Indian Med Gazette 2000;134:156-161.

15. Chakrabarti J, Mandal T, Ghosh TK, Purkayastha S, Roy K. Systemic causes of Menorrhagia. J Obstet Gynecol India 2007;57(5):417-421.

16. Lahiri D, Dasgupta A, Kunda S. Menstrual pattern and fertility status in hypothyroidism. J Obstet Gynaecol India 1996;47:663.

17. Gowri M, Radhika BH, Harshini V, Ramaiaha R. Role of thyroid function tests in women with abnormal uterine bleeding. Int J Reprod Contracept Obstet Gynecol 2014;3: 54-57.

18. Scott JC, Mussey E. Menstrual patterns of myxoedema. Am J Obstet Gynecol 1964 Sep 15;90(2):161-165.

19. Krassas, GE.; Pontikides, NE. The male and female reproductive system in hypothyroidism. In: Braverman, LE.; Cooper, DS., editors. Werner and Ingbar's the thyroid: a fundamental and clinical text. 10th ed. Philadelphia: Lippincott Williams \& Wilkins; 2013, p. 585-586.

20. Pearce EN. Thyroid dysfunction in perimenopausal women. Menopause Int 2007 Mar;13(1):8-13.

21. Kotz HL, Herrmann W. A review of the endocrine induction of human ovulation. Fertil Steril 1961 Jan-Feb;12:96-107. 